\title{
Have paper records passed their expiry date?
}

T

The manager of your local grocery store can instantly determine how many kilos of Ida Red apples are still on the shelves, the use-before dates of every carton of soy milk, the total cash in the cash registers and the dollar value of unsold loaves of bread that will be distributed that evening to the local food bank. Her best friend, a doctor, doesn't know that the elderly patient in his office had a chest $\mathrm{x}$-ray last night when he visited the emergency department, what laboratory tests were ordered - let alone the results or the type and dose of prescribed medications, if any. His patient remembers having an $\mathrm{x}$-ray, but doesn't know the results. He is foggy about the tests and the meds. Neither patient nor doctor knows the date of the patient's last cardiology consultation or recalls off-hand whether he received influenza and pneumococcal vaccines last year. The clinical encounter grinds to a halt while the doctor thumbs through a bulging paper file of barely legible notes.

Why haven't electronic medical records replaced clumsy paper records in offices and hospitals around the country? A recent US survey revealed that $84 \%$ of physicians did not have sufficient electronic access to their patients' records to produce a list of patients by the medications they are taking, ${ }^{1}$ a useful tool to have when regulatory authorities issue "Dear Doctor" warnings.

In describing their motivation for going electronic, 4 physicians in a small group practice in Philadelphia hoped that medical records might eliminate or reduce "frustrating repetitive processes (such as prescription refills) and minimize some of the ways in which we routinely failed to meet patient expectations (such as one of us not knowing what another had said the previous day to a patient on the telephone)." ${ }^{2}$ They also expected and wanted to prepare for working in a future health care system where payment for services would be based on performance, including routine assessments of quality of care.

There are 2 broad requirements for an electronic health records system. First, functionally, the system must be capable of storing and retrieving essential information. This includes storing patient hospital and office records, laboratory results and diagnostic imaging, tracing physician orders, enabling electronic prescriptions, securing electronic communication of voice and email, and performing administrative functions such as submitting claims, booking apचे pointments and performing routine audits of quality of care. Second, a health information system must permit easy communication (interoperability) among health care providers so that an individual patient's information can be shared and used in real time. Systems must be secure and robust so that patients and physicians are confident that patient confidentiality is assured.
As reported by the Philadelphia physicians, patient care does improve, and physician frustration with common repetitive and bothersome tasks such as renewing prescriptions and finding test results is lowered, at least after an initial stressful phase of implementation.

But there are significant barriers to the adoption of electronic patient care records and systems. Perhaps most important among these is that the financial rewards inherent in greater efficiency (say, less duplication of laboratory tests and $\mathrm{x}$-rays) accrue to health insurers, not physician providers. Other barriers are substantial capital investments, varying and untested vendor quality and life expectancy (there are many small companies offering services), and products that are not tailored to specific practice needs. There are also inherent problems in assuring interoperability between practices, hospitals and laboratories that almost always function completely independently of one another.

If implementation is left solely to individual providers of care, then we will never have electronic health records. There is a clear role for governments to provide leadership and to remove financial barriers that place the burden almost exclusively on providers of health care. In the United States, it is estimated that an additional investment of US\$400 billion is needed to create a patient-centred electronic health record that would meet minimal standards of functionality and interoperability. ${ }^{3}$ Assuming the same standards in Canada, an additional investment of Can $\$ 18.7$ billion is needed. Health Infoway, which was established by Health Canada to promote the implementation of electronic health care records, will receive about Can $\$ 200$ million annually over the next 4 years. This falls far short of what we need, even if the provinces contribute an equal amount.

Because access to health information about specific patients in real time by different providers is the central component of an electronic health record, it is an absolute requirement that funding for the adoption of this technology be provided simultaneously to hospitals, clinics, pharmacists and the offices of practising physicians. This is a federal role that will need considerably more investment than has been forthcoming. — CMAJ

\section{References}

1. Audet AM, Doty MM, Shamasdin J, Schoenbaum SC. Measure, learn, and improve: physicians' involvement in quality improvement. Health Affairs 2005;24(3):843-53.

2. Baron RJ, Fabens EL, Schiffman M, Wolf E. Electronic health records: Just around the corner? Or over the cliff? Ann Intern Med 2005;143(3):222-6.

3. Kaushal R, Blumenthal D, Poon EG, Jha AK, Franz C, Middleton B, et al. The costs of a national health information network. Ann Intern Med 2005;143(3):165-73. 